\title{
La alineación verbal del intérprete en un corpus de entrevistas médicas español-italiano
}

\author{
ELEONORA IACONO \\ Universidad de Palermo \\ eleonora.iacono@unipa.it
}

Recibido: 26 de septiembre de 2013

Aceptado: 5 de marzo de 2014

\section{RESUMEN}

El artículo analiza unos fragmentos de un corpus de diez entrevistas médicas, grabadas entre abril y julio de 2009 en el Instituto Valenciano de Infertilidad de Barcelona, caracterizadas por la presencia de un médico de habla española, uno o dos pacientes italianos y una intérprete. Se examina cómo cambia la alineación verbal de esta última, dependiendo de las diferentes situaciones comunicativas que tiene que afrontar. Para lograr este objetivo, se hace hincapié en los estudios de Goffman sobre el footing (o pie) (1981: 325-326), a los de Wadensjö (1998: 91-92) y de Merlini y Favaron (2007: 116-117). Se demuestra que la intérprete no sólo traduce lo que dicen los interlocutores primarios, sino que desarrolla un papel de traductora activa (Leanza, 2007), ya que habla con su propia voz para aclarar dudas o pedir a una de las partes que explique algo.

Palabras clave: interpretación, footing, corpus, entrevista médica.

The interpreter's footing in Spanish-Italian medical interviews

\begin{abstract}
This paper investigates how interpreters' footing can change in the course of intercultural interactions in health-care settings. We have used a corpus (sample) collected in Barcelona, in a well-known clinic providing fertility treatments, over a period of four months, from April to July 2009. The theoretical framework is based on Goffman (1981: 325-326), Wadensjö (1998: 91-92) and Merlini y Favaron (2007: 116-117). Based on the analysis of real examples taken from the spoken interactions, the paper shows how the Spanish-Italian interpreters working at IVI Barcelona does not only translate what the primary interactants say, but, but they are active translators (Leanza, 2007), assuming different roles ranging from principal to responder to direct and indirect recapitulator, according to the communicative situation and to the interactants' demands.


Keywords: interpreter, footing, corpus, medical interview.

Sumario: 1. Introducción. 2. El intérprete como principal. 3. El intérprete se autoselecciona como responder de los pacientes. 4. El intérprete se autoselecciona como responder del médico. 5. Los pacientes seleccionan al intérprete como responder y ejemplos de direct e indirect recapitulator. 6 . Conclusiones.

\section{Introducción}

Goffman (1981: 325-326) define footing (o pie) el conjunto de las posiciones y actitudes que el interlocutor puede asumir con respecto a los otros participantes en la interacción social, a lo que está ocurriendo y a sus propias palabras. De hecho, el hablante puede desarrollar el papel de animador, autor o principal (Íbid.: 124-158), alternativamente: el primero es quien emite una secuencia de palabras sin pensarla él mismo, siendo simplemente un productor de enunciados; el segundo es quien elige lo que se dice y selecciona las palabras que lo expresan, pero no necesariamente es quien las pronuncia; el tercero es el responsable de las palabras (incluso en el caso de que no las haya pensado él), ya que su posición se establece a través de estas (Íbid.: 144-146). Wadensjö (1998: 91-92) perfecciona esta teoría de la enunciación, concebida para el emisor, añadiendo un esquema ideado para el receptor, de modo que junto a las posiciones del hablante de animador, autor y principal propone otras tres que se refieren al oyente, es decir la de reporter, recapitulator y responder. Finalmente, Merlini y Favaron (2007: 116-117) introducen otras dos categorías inherentes a la interpretación, o sea la de narrador y de pseudo-co-principal, respectivamente, según si el intérprete reproduce las palabras de uno de los interlocutores primarios gracias al discurso indirecto o según se incluya en el discurso utilizando la primera persona plural para un enunciado que, al contrario, había sido formulado por el hablante en primera persona singular. Además, cuando un interlocutor primario, eligiendo al intérprete como intermediario, se dirige a él para pedirle que refiera algo al otro, el mediador lingüístico puede adoptar otras dos posiciones, es decir la de direct recapitulator o de indirect recapitulator. En el primer caso, emplea la primera persona singular, reduciendo la distancia que se ha producido entre los dos interlocutores debido al hecho de que hay un mediador que traduce (y que ahora, gracias al uso de la primera persona singular, parece desvanecer). En el segundo, por el contrario, mantiene dicha distancia, ya que utiliza la tercera persona singular.

Lo más importante con respecto a las interacciones interculturales es que uno de los interlocutores primarios puede cambiar su alineación, empezando una conversación monolingüe a dos con el intérprete, que, por consiguiente, asume momentáneamente el papel de interlocutor primario, en detrimento del otro participante en la interacción. Annalie Knapp-Potthoff (1992: 204) sostiene lo siguiente:

Reducing a primary interactant's participant status in such a way can be regarded as face-threatening act in itself. Thus, every action that the mediator or the 
other primary interactant takes in order not to exclude a primary interactant from communication this way is a matter of politeness specific to mediator discourse.

Además, también el intérprete puede decidir cambiar su alineación conversacional y desarrollar transitoriamente el papel de principal: esta estrategia puede servir para preservar su cara profesional, por ejemplo, cuando no ha entendido algo y necesita pedir una explicación a uno de los dos interlocutores ${ }^{1}$.

Otra estrategia, que ya se ha señalado, que puede utilizar el intérprete para proteger su propia imagen (face) es alejarse de lo que ha dicho el emisor primario, desempeñando el papel de narrador y usando expresiones como "él cree que..." o "ella piensa que...", en las que es evidente la voluntad de tutelarse, evitando cualquier clase de compromiso con la idea del otro o, por ejemplo, con la imagen demasiado agresiva que este da en un acto de amenaza a la cara ${ }^{2}$. Además de evitar una asunción de responsabilidad con respecto al acto lingüístico, el intérprete consigue mostrar su empatía hacia el interlocutor cuya imagen está en peligro, confirmando su interés en preservarla. En cambio, cuando el intérprete elige la estrategia opuesta, esto es, mantiene la primera persona, facilita un proceso de reconciliación (Merlini y Favaron 2003: 205-229) que acerca a las partes, reduciendo la inicua distribución de poder $^{3}$, típica de cualquier entrevista médica.

Haciendo hincapié en esta base teórica, veamos ahora cómo estos conceptos pueden aplicarse a un corpus de interacciones reales entre médicos de lengua española y pacientes italianos que se valen de la mediación de intérpretes profesionales de la estructura sanitaria. Este estudio analiza, de hecho, unas visitas extraídas de un corpus de diez entrevistas médicas creado gracias a un período de investigación, de cuatro meses de duración, desarrollado durante 2009 en el Instituto Valenciano de Infertilidad (IVI) de Barcelona, estructura a la vanguardia a nivel internacional en el campo de la reproducción asistida. Son todas primeras visitas en consulta, con tres diferentes médicos de habla española y cuatro intérpretes que trabajan en la clínica; en todos los casos los pacientes son una pareja de marido y mujer, a excepción de la tercera visita, donde sólo hay una mujer soltera. Siempre hay una anamnesis inicial, una ecografía, una prueba de transferencia y una discusión final, mientras que los tratamientos requerido son: fecundación en vitro convencional, fecundación en vitro con ICSI (inyección intracitoplasmática de espermatozoides) y fecundación en vitro con donación de semen o de óvulos. Se analizarán unos fragmentos de conversaciones donde la intérprete deja su papel de traductora para asumir el de principal, responder y direct $\mathrm{o}$ indirect recapitulator.

\footnotetext{
${ }^{1}$ Merlini y Favaron (2007: 106-108) clasifican las intervenciones autónomas del intérprete como ejemplos de la voz de la interpretación y añaden que estas se subdividen en añadiduras, cambios de alineación verbal y gestión de los turnos de habla.

${ }^{2}$ En las últimas décadas se han realizado muchos estudios sobre las acciones que amenazan la imagen pública (AAIPs) en las interacciones verbales, así como las estrategias de cortesía para evitarlas; BROWN y LeVinson (1987), Haverkate (1994), Bravo (2003), Briz (2003) y Albelda (2005), entre otros.

${ }^{3}$ Por "Poder" se entiende la variable sociológica así como argumentada por BROWN y LEVINSON (1987: 76).
} 


\section{El intérprete como principal}

Como se ha subrayado, en las entrevistas médicas el intérprete no se limita a traducir pasivamente, sino que su personalidad y su voz se destacan cuando toma la iniciativa de preguntar algo a los interlocutores primarios o de contestar en su lugar. Por ejemplo, puede asumir el footing de principal para pedir a los pacientes que aclaren algo que no ha entendido; su objetivo es no cometer errores en su traducción o ahondar en un tema que considere relevante, para que los participantes en la entrevista puedan comprender mejor. Veamos un ejemplo:

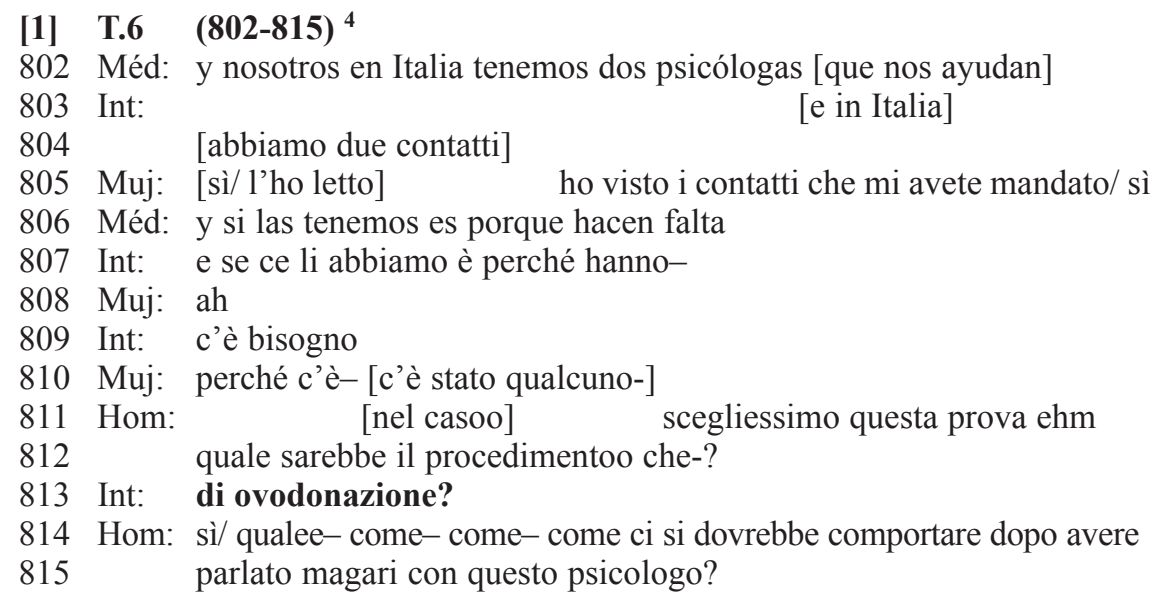

En la línea 813, la intérprete no está traduciendo las palabras del médico, sino que está tomando la iniciativa de preguntar al paciente si se refiere al tratamiento de ovodonación. Tratar de conseguir una información clara y correcta es también una manera de tutelar su propia imagen profesional, porque reduce el riesgo de errores de traducción. Presentamos otro ejemplo en el cual la intérprete advierte la necesidad de aclarar algo con los pacientes, asumiendo la alineación de principal:

[2] T.5 (71-73)

71 Méd: perfecto/ ¿en la última congelaste seis embriones?

\footnotetext{
4 Todos los ejemplos presentados están numerados entre corchetes, consecutivamente. La transcripción a la cual pertenecen los extractos se indica con T.1, T.2, T.3... La numeración de las líneas se indica tanto entre paréntesis, al lado del número del ejemplo y del número de la transcripción, como en el margen de cada línea. Para respetar la privacidad de los informantes, se ha decidido no indicar en las transcripciones el nombre de los pacientes, de las intérpretes y del personal médico y de enfermería participante a la interacción. Se identifica, por tanto, caso por caso, a la intérprete con la abreviación "Int", al médico con "Méd", a la enfermera con "Enf" y a la pareja de marido y mujer respectivamente con "Hom" y "Muj". Todos los nombres pronunciados en el curso de las grabaciones han sido sustituidos en la transcripción por seudónimos. Se recurre, además, a la letra marcada en negrita para señalar los elementos sobre los cuales se quiere atraer la atención. Por último, el sistema de símbolos es el utilizado por Briz y el Grupo Val.Es.Co (2002).
} 
72 Muj: sì ma non embrioni/ lo stadio prima ehmm-

73 Int: tre embrioni o ovociti? cioè dopo la fecondazione o prima?

En otras ocasiones la intérprete se dirige al médico para pedirle una explicación:
[3] T.7 (144-152)
144 Méd: hay menos lista de espera cuanto más se parece a mí la receptora
145 Int: ¿perdón?
146 Méd: cuanto más se parece a mí la receptora
147 Int: ((se ríe)) ¿menor es la lista de espera?
148 Méd: ((asiente con la cabeza))
149 Int: aah// ci sono praticamente/ cioè nella lista d'attesa/ più praticamente
150 comee- cioè più somiglia più alla- alle caratteristiche fisiche
151 mediterranee/ ${ }^{\circ}$ per una [lista d'attesa minore ${ }^{\circ}$ ]
152 Muj: [mmh]

Solo después de la repetición del médico (146), la mediadora puede traducir correctamente para los pacientes (149-151), sin riesgos para su propia imagen.

Otro momento delicado se produce cuando los pacientes parecen entender lo que dice el médico sin necesitar ayuda, porque la tarea del intérprete, en este caso, es comprobar si merece la pena intervenir con su traducción o si, por el contrario, esto sería fuera de lugar. Su voz puede, entonces, emerger para subrayar que, si lo necesitan, está a su disposición para traducir:

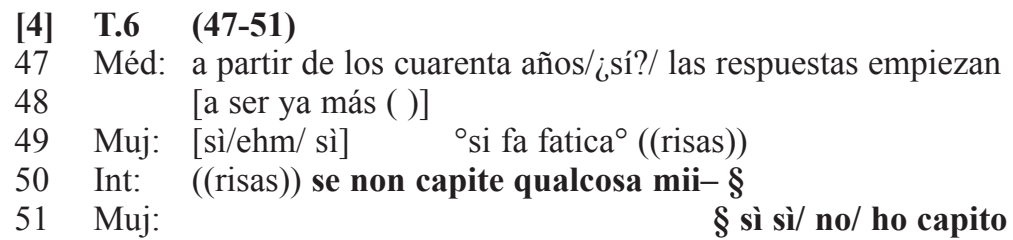

Como los comentarios de la mujer demuestran que ella entiende lo que el médico le dice (línea 49), la intérprete se limita a tutelar su imagen profesional de traductora que, teóricamente, tendría que intervenir para traducir al italiano, afirmando "se non capite qualcosa mii-" (50). Además, las risas de la intérprete testimonian su voluntad de atenuar su dificultad frente a la falta de necesidad de su intervención. La paciente, a su vez, presta atención a la cara positiva de la intérprete, tranquilizándola sobre el hecho de que ya lo ha entendido todo (51: "sì sì/ no/ ho capito").

\section{El intérprete se autoselecciona como responder de los pacientes}

Hasta aquí el examen de la alineación de principal. Otro caso interesante ocurre cuando uno de los pacientes pregunta algo al médico y el intérprete, en lugar de traducir para él, contesta directamente, autoseleccionándose como responder: 
[5] T.3 (461-466)

461 Muj: posso fare una domanda?

462 Méd: sí claro

463 Muj: ma se la tuba è chiusa come fa ehm l'ovulo comunque a passare? cioè

464 [la mestruazione-]

465 Int: $\left[{ }^{\circ}\right.$ non passa $\left.{ }^{\circ}\right]$

466 Méd: no pasa

Nótese que en este fragmento la intérprete habla en voz baja (465), casi susurrando, porque se da cuenta de que la tarea de aclarar las dudas y las curiosidades de los pacientes le correspondería al médico y que, interviniendo en su lugar, podría usurpar su papel y amenazar su imagen. A continuación, el médico explica a la paciente lo que pasa con el cuerpo de la mujer durante la menstruación, pero, al cabo de un rato, la intérprete interviene otra vez para contestar a una pregunta en lugar del especialista:

\section{[6] T.3 (485-492)}

485 Muj: ho capito/ quindi non è- la mestruazione non è dovuta all'ovulo[che=]

486 Int:

$\left[{ }^{\circ} \mathbf{n o}^{\circ}\right]$

487 Muj: = non si impianta $\S$

488 Méd: $\quad \S$ no $\S$

489 Muj: $\quad \S$ è soltanto l'endometrio che sì è preparato

490 [a riceverlo]

491 Int: $\left[{ }^{\circ}\right.$ esatto $\left.^{\circ}\right]$

492 Méd: lo que- lo que sangra esto es el endometrio

También en este caso la intérprete superpone, dos veces (líneas 486 y 491), su voz a la de la paciente para responder, en voz baja, en lugar de traducir para el médico y esperar que conteste él. Veamos qué pasa a continuación:

\section{[7] $\quad$ T.3 (705-717)}

705 Méd: vamos al quirófano

706 Int: si sale in sala operatoria

707 Muj: ah

708 Méd: y hacemos el pick-up

709 Int: e facciamo il il pick-up

710 Méd: y iqué es el pick-up?

711 Int: prelievoo-

712 Méd: y bajo anestesia

713 Int: quindi con anestesia

714 Muj: totale?

715 Int: totale

716 Méd: total/ dura más o menos veinte minutos

717 Int: che dura circa dieci venti minuti

El médico está exponiendo las etapas necesarias para llegar al "pick-up", pero, como se da cuenta de que los pacientes podrían desconocer el término inglés, inten- 
ta introducir la explicación de lo que es, gracias a una falsa pregunta (710: "y ¿qué es el pick-up?"). La intérprete, a su vez, no traduce la falsa pregunta del médico, sino que contesta directamente, aclarando, de hecho, lo que significa "pick-up" (711: "prelievoo-"), así que el ginecólogo puede omitir la aclaración que había pensado ofrecer a la pareja italiana. Por lo tanto, el médico sigue informando a los pacientes sobre la necesidad de que el pick-up se realice bajo anestesia. Cuando la mujer pregunta si tiene que someterse a una anestesia general (714), la intérprete responde otra vez directamente, sin esperar al médico (715).

Hasta aquí las intervenciones autónomas de la intérprete no causan ningún problema para los interlocutores primarios. Sin embargo, veamos qué ocurre, en la misma entrevista, cuando la intérprete aclara directamente una duda de la paciente sin traducir para el médico y este último interviene para comprender qué está preguntando la mujer:

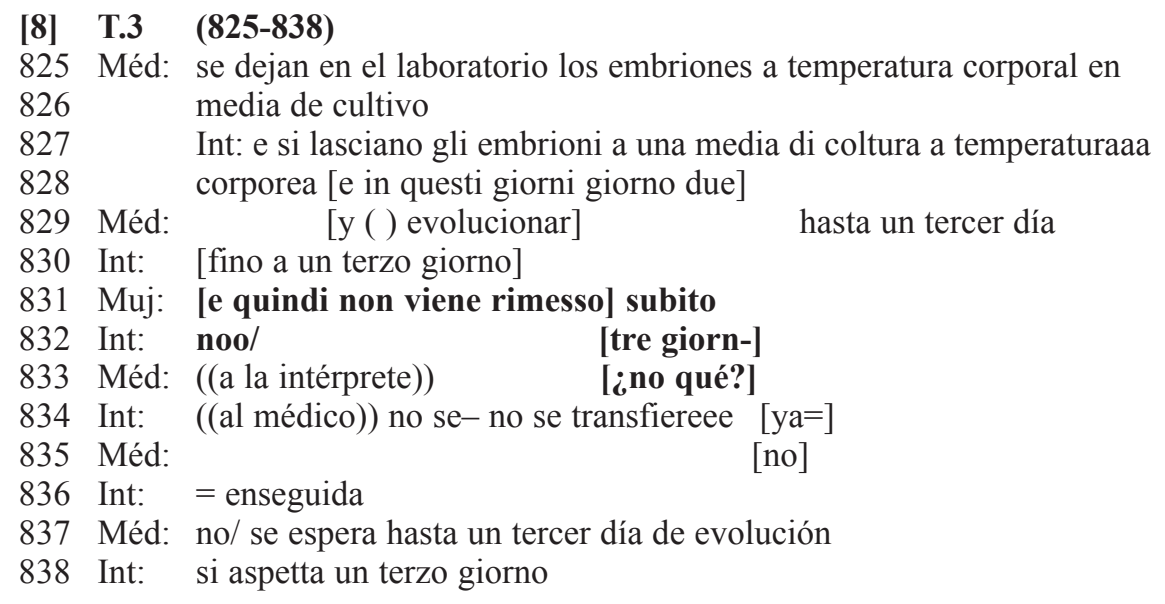

En la línea 831, la paciente pregunta si los embriones fecundados con ICSI se transfieren en seguida al útero. La intérprete conoce la respuesta, porque no solo ella trabaja en la clínica desde hace unos años, sino que en la misma entrevista el médico ha comentado que los embriones se dejan evolucionar hasta un tercer día (829) y ella ha traducido ya este turno de habla (830). Por lo tanto, en vez de traducir la pregunta de la paciente (831: "[e quindi non viene rimesso] subito"), contesta directamente (832: "noo/ [tre giorn-]"), provocando la reacción del médico, que interrumpe su exposición para preguntar a la intérprete por qué ha contestado que no (833: "[¿no qué?]”) y, después de la explicación de la mediadora (834-836), interviene para contestar él mismo a la mujer (837: "no/ se espera hasta un tercer día de evolución"). Evidentemente, de ese modo el médico retoma el control de la interacción y restablece su poder. Veamos otro ejemplo:

\section{[9] T.3 (990-1010)}

990 Méd: y lo que decíamos de las hormonas// que la fsh está en diez

991 Muj: $\mathrm{mmh}$ 


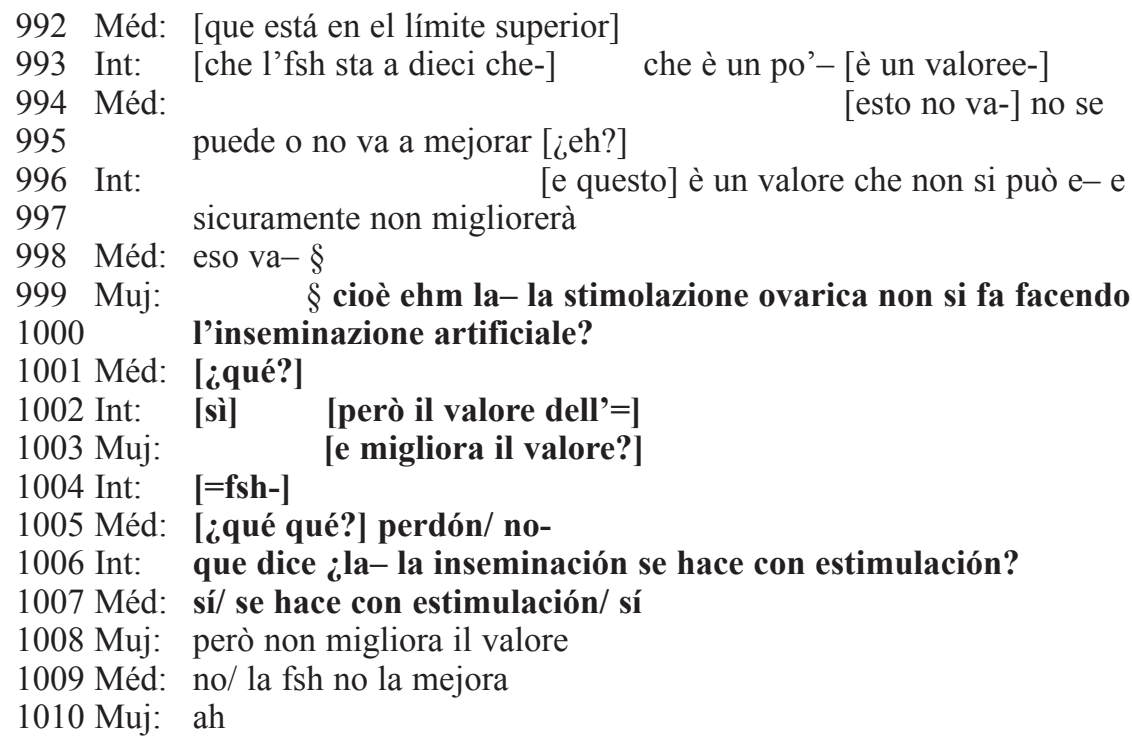

En la línea 999 de la transcripción número 3, la paciente interrumpe al médico para preguntarle si la inseminación artificial necesita estimulación ovárica, pero, de nuevo, la intérprete no traduce, sino que contesta directamente (1002), aunque está claro que el médico no ha entendido y le está pidiendo una traducción (1001: "[¿qué?]”). Cuando el médico se da cuenta de que la intérprete, en lugar de traducir la pregunta al español, está explicando la terapia a la mujer (1002-1004), interviene otra vez, superponiendo su voz a la de la mediadora lingüística: aunque el ginecólogo pida disculpa por interrumpir, él reafirma, implícitamente, su derecho a saber cuáles son las dudas de la paciente y a contestarle directamente (1005: "[¿qué qué?] perdón no-"). La intérprete, de hecho, al final, traduce el turno de habla de la mujer al español (1006: “que dice ¿la- la inseminación se hace con estimulación?”), de manera que el médico puede contestar a la pregunta (1007: "sí/ se hace con estimulación/ sí”). Está claro que la imagen del médico, excluido momentáneamente de la conversación, ha sufrido una amenaza, así que tiene la necesidad de restablecer su autoridad, pidiendo explícitamente a la intérprete que traduzca.

\section{El intérprete se autoselecciona como responder del médico}

Un caso opuesto a los examinados hasta ahora se produce cuando el intérprete no traduce lo que el médico pregunta a los pacientes sino que contesta directamente en su lugar, excluyéndolos, momentáneamente, de la conversación:

[10] T.6 (183-225)

183 Méd: cuando se trabajó con vuestroos- en los otros ce- en los otros centros/ $184 \quad$ ¿eh?/ la primeraa vez se utilizó la fecundación en vitro convencional 185 Int: [la prima volta fiv normale] 


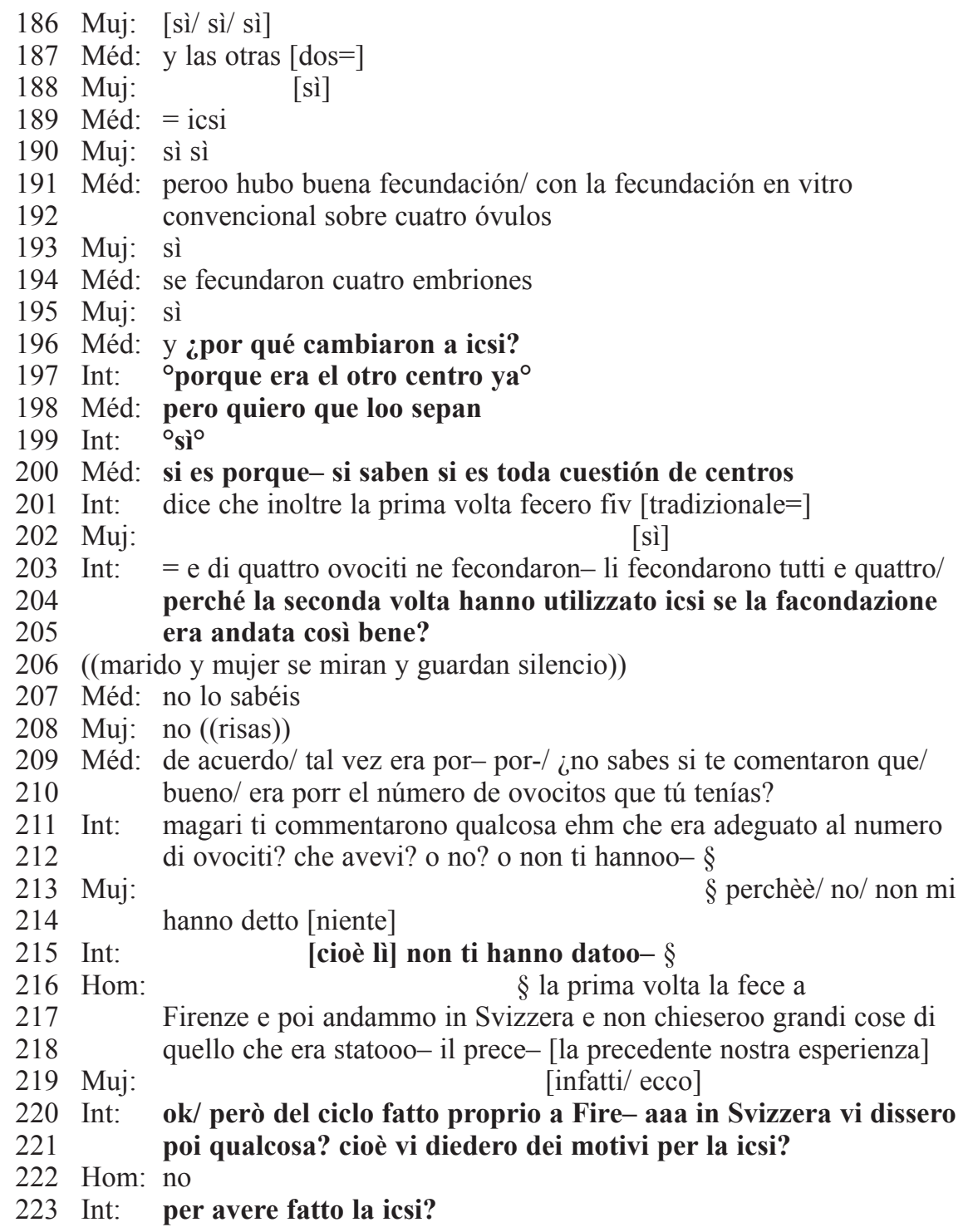

Con respecto a lo ocurrido en los otros centros antes de que la pareja llegara a IVI Barcelona, el médico les pregunta por qué la segunda vez no se utilizó la fecundación en vitro convencional y se decidió cambiar a ICSI (196). Como la intérprete ya conoce la razón, contesta directamente, aunque hable en voz baja porque sabe que está asumiendo un papel de responder, o sea de interlocutor primario, que no le correspondería (197: "oporque era el otro centro ya"). Por lo tanto, empieza una conversación monolingüe a dos entre la médico y la intérprete, en la que la primera explica a la segunda que quiere comprobar si los pacientes están al tanto del motivo o si, por el contrario, lo ignoran (198 y 200). Cuando, por fin, la intérprete entien- 
de la intención de la doctora, traduce para los pacientes (204-205). Además, ya que ahora sabe que el objetivo prioritario de la doctora es que la pareja demuestre haber entendido lo que pasó en el otro centro, no solo sigue traduciendo lo que ella dice (211-212), sino que toma incluso la iniciativa de hacer más preguntas sobre el tema, asumiendo el papel de principal y sustituyendo al médico en la conducción de la entrevista $(215,220-221$ y 223$)$.

Veamos otro caso en el que otra intérprete asume el footing de responder para aclarar un malentendido y corregir una información errónea:

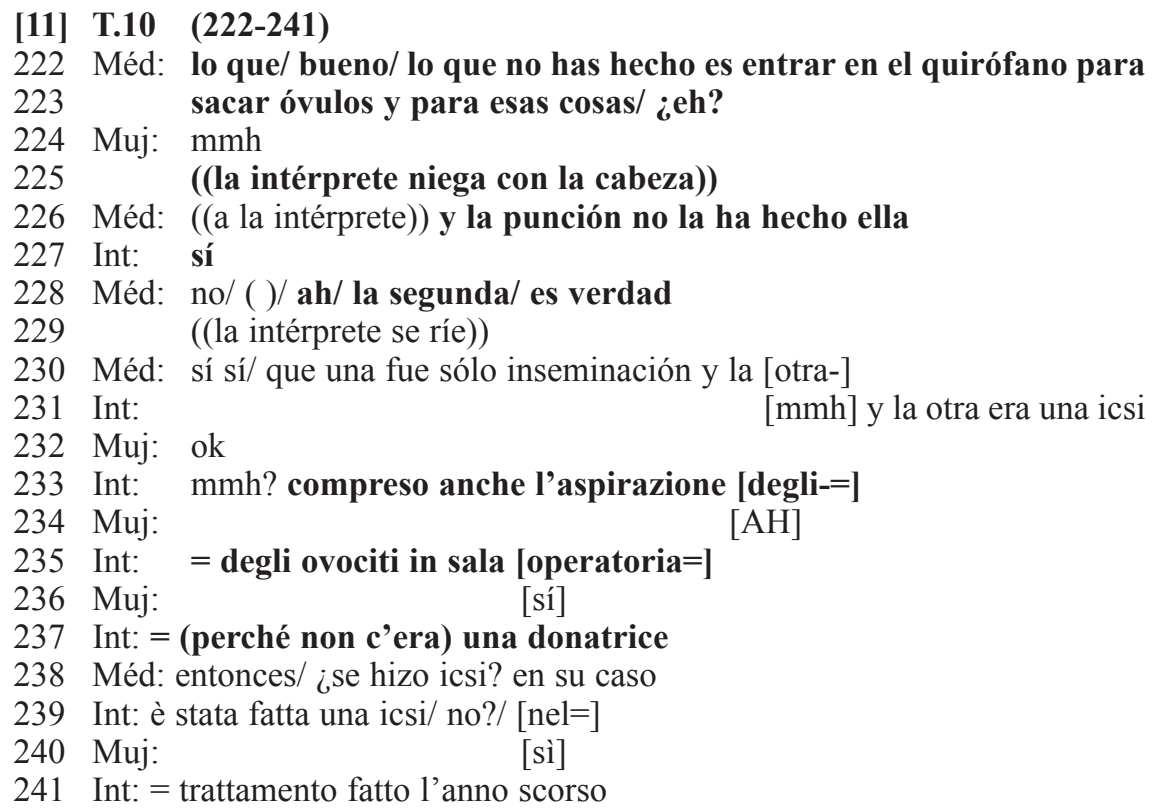

En las líneas 222-223 la doctora sostiene que la mujer nunca ha entrado en el quirófano para que le extrajeran óvulos. La intérprete sabe que ella se está equivocando, por lo tanto, en vez de traducir, niega con la cabeza (225), mientras la otra reafirma que a la paciente nunca le han practicado una punción (226). Cuando la mediadora lingüística, por fin, le dice que sí (227), la médico se da cuenta de su error, ya que la primera vez hubo inseminación mientras que la segunda hubo ICSI, como repite también la intérprete (228-230-231). Nótese que la mediadora ni traduce la afirmación incorrecta de la doctora con respecto a la punción, ni explica a los pacientes que se había equivocado y que ella le ha señalado el error. Por el contrario, toma la iniciativa de completar la frase del médico con la información correcta (233-235-237: "mmh? compreso anche l'aspirazione degli- degli ovociti in sala operatoria (perché non c'era) una donatrice"); de ese modo, en su traducción afirma algo diferente de lo que ha dicho el interlocutor primario: su objetivo es el éxito de la comunicación. Por lo tanto, también en este caso la intérprete está actuando como traductora activa (Leanza 2007), comprobando la exactitud de la información y rectificándola si hace falta. De esto se deduce que los intérpretes desempeñan un papel 
complejo en las interacciones interculturales, ya que no traducen pasivamente, sino que son los garantes de las interacciones mismas.

\section{Los pacientes seleccionan al intérprete como responder y ejemplos de direct e indirect recapitulator}

En los casos analizados hasta ahora, el intérprete se autoselecciona como responder, ya que elige, espontáneamente, responder en lugar del médico o de los pacientes. Sin embargo, otra posibilidad es que uno de estos lo escoja como interlocutor, haciéndole una pregunta. Por ejemplo, en el siguiente fragmento, el paciente pide a la mediadora que repita una palabra española que le gustaría aprender:

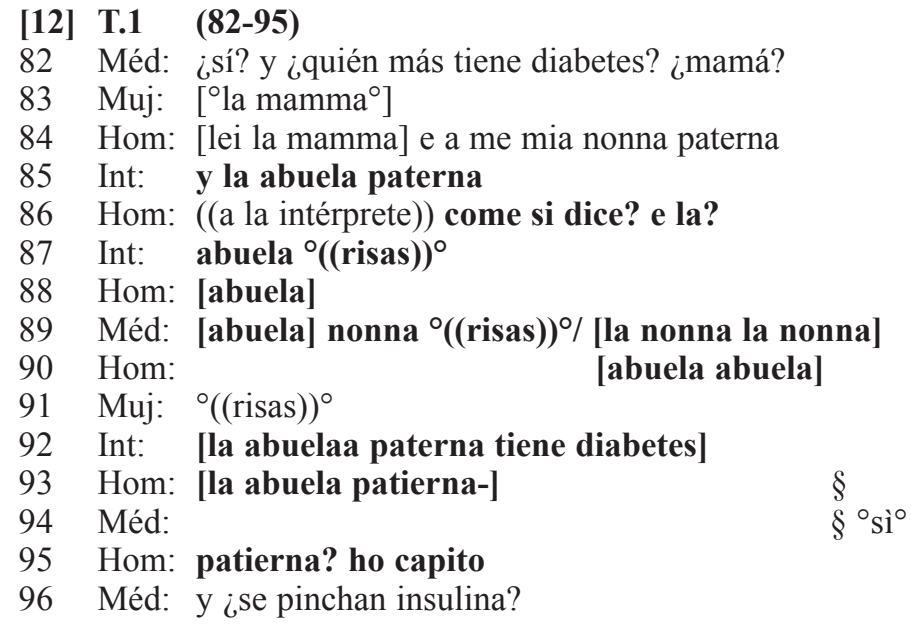

El marido pregunta a la intérprete cómo se dice "nonna" en español (86) y ella le responde (87). Nótese que esto da lugar a una breve pausa, en la que todos se ríen (87,89 y 91) e incluso el médico repite en español y en italiano la palabra (89: “[abuela] nonna ${ }^{\circ}((\text { risas }))^{\circ} /$ [la nonna la nonna]"). Al final, él restablece el orden y sigue preguntando a los pacientes si se pinchan insulina (96).

Un episodio muy interesante ocurre en la trascripción 2: el médico contesta al teléfono y la paciente, que está preocupada porque no se ha podido efectuar la prueba de transferencia ya que no fue posible pasar con ninguna de las cánulas, hace unas preguntas a la intérprete:

[13] T.2 (47-71)

47 Méd: ((coge el teléfono que le pasa la enfermera)) ahora hablo un

48 segundo con la doctora/ permiso/ ¿eh?

49 ((el médico habla al teléfono))

50 Muj: ((a la intérprete mientras el médico habla al teléfono y no les

51 escucha)) ma quindi sta dicendo che-

52 Int: di fare un'isteroscopia/ qui non è riuscito a passare 
53 Muj: quindi che- ci so- ci sono- problemi? ((risas))

54 Int: nooo/ si fa un'isteroscopia che vedanoo- [se ci sono o no=]

55 Muj: [e quindi ci sono possibilità-]

56 Int: = e a volte con l'isteroscopia quel che fanno anche è dilatare un

57 po' il collo/ fare una specie di ( ) toglierlo/ ${ }^{\circ}$ se ci sonoo si può

$58 \quad$ correggere $^{\circ}$ ((risas))

59 Muj: si può correggere ((risas))

60 Int: sì sì sì// oggi non è riuscito a passare/ peròò-

61 Muj: quindi non vuol dire che non passerà dopo/ cioè che nonn- non ci

62 dobbiamo provare/ no?

63 Int: noo/ noo

64 Muj: ah ecco

65 ((pausa de 10" mientras el médico sigue hablando al teléfono))

66 Méd: perdonen// entonces/ por eso que es importante hacer laa- la

67 histeroscopia/ ¿eh?/ que la puede hacer en Italia

68 Int: ${ }^{\circ} \mathrm{mmh}^{\circ}$

69 Méd: [que no es un problema]

70 Int: [che è importante] fare questa isteroscopia sta dicendo/ che può

71 fare praticamente in Italia

También en este caso la paciente selecciona a la intérprete como interlocutor primario: como ella trabaja en el entorno médico-sanitario y conoce bien las técnicas que pueden solucionar el problema de la mujer, está en condiciones de contestar y puede explicar a la pareja que una histeroscopia podría ayudarles (54-58). Cuando el médico cuelga el teléfono, sin embargo, todos asumen otra vez sus roles institucionales, así que él reanuda su discurso donde lo había dejado (66-67) y la intérprete deja de ser un interlocutor primario con su propia voz y vuelve a traducir las palabras del ginecólogo (70-71). Algo parecido ocurre en la trascripción 8, ya que la mujer, mientras el médico habla por teléfono, selecciona a la intérprete como interlocutor primario y, por lo tanto, responder:

[14] T.8 (740-770)

740 Méd: nosotros ha- haremos hatching/ aspiración de fragmentos/ si vemos

741 que los embriones necesitan ayuda

742 Muj: ${ }^{\circ} \mathrm{mmh}^{\circ}$

743 ((el teléfono suena))

744 Méd: ¿eh?/ necesitan ayuda- necesitan ayuda porque nonn- algo no- no

745 va/ [ieh?]

746 Muj: ((se ríe)) [non ce] la fa da solo

747 ((el médico contesta al teléfono))

748 Int: sì/ lo fanno solo per- per migliorare la qualità quando gli embrioni

749 sono così così

750 Muj: ho capito male o ha detto chee probabilmente nel nostro caso

751 farà il trasferimento in quinta giornata

752 Int: esatto//sì/ perché questo permette di selezionare meglio gli embrioni

753 Hom: ( ) le cellule quattro/ otto/// quello che non permette l'Italia

754 Muj: no/ blastocisto sono più di sessantaquattro mi sembra

755 Int: sì perché inn- in terza giornata/ quando loro li trasferiscono 
756

757

758 Muj:

759

760 Int:

761 ((el médico cuelga el teléfono))

762 Muj:

763 Int:

764

765

766 Int:

767

768

769

770 avvenga fuori dalla [donna=]

$$
\text { Muj: = non è differente/ no? }
$$
tiempo fuera del útero normalmente gli embrioni hanno tra sei e dieci cellule/ $\mathrm{mmh}$ ?// invece/ blastocisto già è uno stadio più avanzato

eh/ poi gli puoi chiedere se c'è differenza/ ehm/ a livello di-/ ehm/ di gravidanze ehm fra in terza e quinta giornata?/ [cioè=]

$[\mathrm{mmh}]$

Muj: = perché il fatto che il-il- il-/ diciamo/ il processo di crescita$$
[\mathrm{mmh}]
$$

Int: a nivel de embarazo de-de niñoos normales ¿el hecho de transferir en quinto día/ ehm/ influye?/ es decir/ como el embrión está más

En las líneas 750-751, la paciente pregunta a la intérprete si ha entendido bien lo que ha dicho el médico, es decir, que la transferencia de los embriones se hará en el quinto día. Comienza un diálogo entre la pareja y la mediadora y esta última contesta a sus preguntas y les explica qué significa "blastocisto" (755-757), desempeñando un papel que le correspondería al médico. Finalmente, cuando la mujer pide a la intérprete que pregunte al médico si el hecho de transferir en quinto día influye sobre el niño (758-759-762-764-765-767), la intérprete asume otra vez su papel de traductora (768-770). Nótese que en esta misma entrevista la paciente a menudo dirige la palabra a la intérprete para que ella pregunte algo al médico, incluso cuando este último no está hablando al teléfono. Por supuesto, en esos casos no selecciona a la intérprete como responder, ya que la verdadera pregunta es para el ginecólogo. Veamos un ejemplo:
[15] T.8 (118-125)
118 Méd: tratamientos tiene dos/// dos fecundaciones en vitro conn una fiv y
119 una icsi/// decapeptyl depot
120 Int: sta vedendo i trattamenti che avete fatto in [Italia]
121 Muj:
122 Int:
124 si quieres verlas ha traído las fotos de- de las ecografías que le
125 hicieron durante los controles de la estimulación
[digli] che se vuole ho
delle-le foto dell'ecografie see- che le ho [portate]

[portate]
[dice] que
e las ecografías que le
ulación

En la línea 121, la mujer utiliza la expresión "digli che", con la que, de hecho, se aleja del médico, eligiendo explícitamente a la intérprete como intermediario. En el fragmento 15, la intérprete mantiene dicha distancia, ya que asume el papel de indirect recapitulator (123: "dice que"). Lo mismo ocurre en el caso siguiente (794: "dice que"):

\section{[16] T.8 (791-796)}

791 Méd: [¿eh?] 
792 Muj: $\quad\left[{ }^{\circ}\right.$ senti $\left.{ }^{\circ}\right]$ gli puoi dire per cortesia/ prima che lui prenda qualunque

793 decisione/ che io la prima stimolazione sono stata molto male

794 Int: $\mathrm{mmh} /$ dice que la primera estimulación do- $\S$

795 Muj:

796 Int: que estuvo muy mal después del tranfer

$\S$ dopo il transfer

Otras veces, al contrario, la mediadora reduce la distancia entre médico y pacientes, gracias a la alineación de direct recapitulator:

[17] T.8 (529-538)

529 Méd: [eso lo tengo claro]

530 Muj: [quindi lui ritiene che non siaa] da abbattersi perché queste duee

531 cose-cioè non è- ci sono problemi di attecchimento di questi

532 embrioni/ era anche la qualità che non era [granchè?=]

533 Int:

534 Muj: = chiediglielo un po'

535 Int: ¿túú piensas que no ha sido un problema deee- de implantación ooo-

$536 \quad[\mathrm{de}=]$

537 Méd: [no]

538 Int: = de calidad?

En la línea 535, de hecho, la intérprete pregunta directamente al médico (“¿túú piensas que"), evitando expresiones como "está preguntando", etc.

\section{Conclusiones}

Durante el analisis de las entrevistas médicas mediadas por cuatro intérpretes, se ha subrayado que en esta clase de interacciones interculturales el papel de quien traduce es muy complejo y delicado. De hecho, examinando las transcripciones, se ha podido observar que las intérpretes tuvieron que tener en cuenta las diferentes exigencias de los pacientes, de los médicos y de sus propias imágenes profesionales: no fueron simples traductoras que facilitaron la comunicación entre personas que no hablaban el mismo idioma, sino que tuvieron que desempeñar diferentes papeles, según les requerían las circunstancias. Por lo tanto, la idea de un intérprete como un canal aséptico que permite el trasvase de información es restrictiva e insatisfactoria, ya que hemos comprobado que su alineación cambia continuamente por diferentes razones. Por ejemplo, cuando algo no está claro y son necesarias más explicaciones, el intérprete puede asumir el footing de principal, preguntando algo con su propia voz al médico o al paciente, empezando una conversación monolingüe, que excluye momentáneamente al otro interlocutor primario. Aunque teóricamente esto podría parecer insólito, se ha observado que en la práctica se produce con frecuencia, porque el intérprete, siendo no solo un mediador lingüístico, sino también el garante de la comunicación, tiene que intervenir cuando lo considera necesario, para evitar malintendidos o aclarar dudas. De este modo, se hace cargo de las exigencias de todos los interlocutores primarios. Además, en el análisis se ha estudiado también el 
caso en que el intérprete se autoselecciona responder del médico o de los pacientes y se ha subrayado que, aunque en las entrevistas la intención de las mediadoras era garantizar una información clara y correcta, en ocasiones los médicos, no entendiendo lo que ellas con sus proprias voces estaban explicando a los pacientes, intervinieron para darse cuenta de lo que estaba ocurriendo y restablecer su poder sobre la interacción. Esto nos sugiere que, aunque de vez en cuando es necesario que el intérprete hable con su propia voz, nunca debe exagerar desempeñando un papel que no le corresponde. Por supuesto, solo el contexto puede indicar cómo actuar en cada circustancia, protegendo las imágenes de todos.

Además, en las entrevistas se ha analizado el caso en que los mismos interlocutores primarios han pedido a las mediadoras que fueran responders para que disiparan sus dudas. De hecho, ya que los intérpretes acercan a los pacientes al médico gracias a su mediación, es normal que a veces sea más facil para los primeros preguntarles directamente a ellos, como si fueran aliados que los confortan y ayudan.

En conclusión, de este estudio se deduce que el intérprete tiene que cuidar incesantemente que la interacción tenga éxito, actuando como traductor activo, dispuesto a cambiar su alineación verbal en consonancia con la situación y con la marcha de la entrevista, para que todos y cada uno comprenda y pueda alcanzar sus objetivos comunicativos.

\section{Referencias bibliográficas}

Albeda Marco, M., «El refuerzo de la imagen social en conversaciones coloquiales en español peninsular: la intensificación como categoría pragmática», en: BRAVO, D. (ed.), Estudios de la (des)cortesía en español: categorías conceptuales y aplicaciones a corpora orales y escritos. Buenos Aires: Editorial Dunken 2005, 93-118.

Angelelli, C. V., Revisiting the Interpreter's Role. A Study of Conference, Court, and Medical Interpreters in Canada, Mexico, and the United States. Amsterdam/Philadelphia: John Benjamins Publishing Company 2004.

ARNDT, H. / JANNEY, R. W., «Intracultural tact versus intercultural tact», en: WATTS, R. J. / IDE, S. / Ehlich, K. (eds.), Politeness in Language: Studies in its History, Theory and Practice. Berlin-New York: Mouton de Gruyter 1992, 21-43.

BAKER-Shenk, C., «The interpreter: machine, advocate or ally?», en: Moeller, J. P. (ed.), Expanding Horizons, Silver Spring, MD: RID Publications 1992, 119-140.

BoLDEN, G. B., «Toward understanding practices of medical interpreting: Interpreters' involvement in history taking», Discourse Studies 2.4 (2000), 387-419.

Вот, Н., «The myth of the uninvolved interpreter interpreting in mental health and the development of a three-person psychology», en: BRunetTe, L. / Bastin, G. / Hemlin, I. / Clarke, H. (eds.), The Critical Link 3: Interpreters in the Community, Amsterdam-Philadelphia: Benjamins 2003, 27-35.

BraVO, D., «Actividades de cortesía, imagen social y contextos socioculturales: una introducción», en: Bravo, D. (ed.), Actas del Primer Coloquio del programa EDICE. La perspectiva no etnocentrista de la cortesía: identidad sociocultural de las comunidades hispanohablantes. Stoccolma: Stockholms Universitet 2003, 98-108.

BRIZ, A., «La estrategia atenuadora en la conversación cotidiana española», en: BRAVo, D. (ed.), Actas del Primer Coloquio del programa EDICE. La perspectiva no etnocentrista 
de la cortesía: identidad sociocultural de las comunidades hispanohablantes. Stoccolma: Stockholms Universitet 2003, 17-46.

Briz, A. / Grupo VAl.Es.Co, «Corpus de conversaciones coloquiales», Anejo de la Revista Oralia. Madrid: Arco-Libros 2002.

Brown, P. / Levinson, S. C., Politeness. Some Universals in Language Usage. Cambridge UK: Cambridge University Press 1987.

CAMBridge, J., «Interlocutor roles and the pressures on interpreters», en: VALERO GARCÉS, C. / Mancho BARÉS, G. (eds.), Nuevas necesidades para nuevas realidades. Madrid: Universidad de Alcalá 2002, 119-123.

CAmbridge, J., «Unas ideas sobre la interpretación en los centros de salud», en: VAlero Garcés, C. (ed.), Traducción e interpretación en los Servicios Públicos. Contextualización, actualidad y futuro. Granada: Comares 2003, 3-30.

Fairclough, N., Discourse and Social Change. Cambridge: Polity Press 1992.

Goffman, E., Forms of Talk. Oxford: Blackwell 1981.

Grupo VAl.Es.Co., «Un sistema de unidades para el estudio del lenguaje coloquial», Oralia 6 (2003), 7-61.

Hortal, A., Ética professional de traductores e intérpretes, Bilbao: Desclée de Bouwer 2007.

Knapp-Potthoff, A., «Secondhand politeness», en: Watts, R. J. / Ide, S. / EhLICH, K. (eds.), Politeness in Language: Studies in its History, Theory and Practice. Berlin-New York: Mouton de Gruyter 1992, 203-220.

LÁzaro Gutiérrez, R. / VAlero Garcés, C., «Intercultural Communication in Healthcare Settings: A Case Study», en: Mourón Figueroa, C. / Moralejo Gárate, T. (eds.), Studies in Contrastive Linguistics: Proceeding of the Fourth International Contrastive Linguistics Conference Santiago de Compostela 2006, 493-508.

Haverkate, H., La cortesía verbal: estudio prgmalingüístico. Madrid: Editorial Gredos 1994.

LEANZA, Y., «Roles of community interpreters in pediatrics as seen by interpreters, physicians and researchers», en: PöchHACKer, F. / Shlesinger, M. (eds.), Healthcare Interpreting. Amsterdam: John Benjamins Publishing Company 2007, 11-34.

MERLINI, R. / FAVARON, R., «Community interpreting: re-conciliation through power management», The Interpreters' Newsletter 12 (2003), 205-229.

MERLINI, R. / FAVARON, R., «Examining the 'voice of interpreting' in speech pathology», en: PöchHacker, F. / Shlesinger, M. (eds.), Healthcare Interpreting. Amsterdam: John Benjamins Publishing Company 2007, 101-137.

Morelli, M. / De Luise, D., (eds.), Tracce di Mediazione, Polimetrica Publisher 2010.

PÖCHHACKER., «Getting organized: The evolution of community interpreting», Interpreting, 4, 1 (2002), 125-141.

PöChHACKeR, F., Introducing Interpreting Studies. London: Routledge 2004.

VAlero Garcés, C. / MARTIN, A., Crossing borders in community interpreting: definitions and dilemmas. Amsterdam-Philadelphia: John Benjamins 2008.

WADENSJÖ, C., Interpreting as Interaction. London/New York: Longman 1998. 